\title{
Designing Jobs to Make Employees Happy? Focus on Job Satisfaction First
}

\begin{abstract}
This paper examines the effects of job task characteristics and job satisfaction on subjective wellbeing, often referred to as happiness, among Japanese employees. Because past research has recognized happiness as a source of greater performance and on account of recent events related to 'karoshi' - or death by overwork, its antecedents in the workplace are of great interest for both research and practice.

This research, using conditional process analysis with data gathered from Japanese managers and front-line workers within Japanese firms in Japan, found that job satisfaction fully mediates the relationship between job task characteristics and subjective well-being. Among job satisfaction factors, job satisfaction-self-accomplishment and -relatedness displayed the strongest mediating influence between job task characteristics and positive well-being.

First, these findings suggest that companies cannot rely on job design alone to directly foster employee well-being but must ensure that task characteristics translate into work-related outcomes, such as job satisfaction. Second, at least for Japanese employees, careful attention to job design fostering job satisfaction-self-accomplishment and -relatedness is necessary to enhance subjective well-being. These results indicate that job satisfaction plays a central role in the relationship between job design and well-being.
\end{abstract}

Keywords: Subjective well-being, job task characteristics, job satisfaction, Japan

\section{Introduction}

Changes in both demographic and economic contexts in Japan are calling for a reassessment of the relation between organizational performance and individual well-being in the country. Japan experienced rapid growth after the war, and with it came the worry of overpopulation for policymakers in the 1950s and 1960s (Tadokoro, 2014). The situation has now reversed with tapering growth and demographic decline. The Japanese population is today facing the dual problem of ageing and low birth rate, leading to its drop. Specifically, the Japanese Ministry of Health, Labor and Welfare is projecting the working age population (ages 15-64) to fall from $64 \%$ to $51 \%$ of the 
population between 2012 and 2060 (Williams, 2013).

Fast economic growth after the war led Japanese companies to adopt lifetime employment and seniority-based promotion as human resource tools to attract and retain employees, "buying" their commitment. Since the economic bubble burst of the 1990s, however, these two human resources management characteristics of Japanese companies have declined. In fact, part of the management style of Japanese companies is changing. It is shifting from a seniority-based system to a performancebased one (Miyamoto, 2009). This tendency has increased in the 2000s, under the dual influence of Carlos Ghosn's revival of Nissan and of new global standards in corporate governance following the 2001 Enron scandal. In turn, this change of management style has given birth to a sense of insecurity in the minds of employees, and even to mental depressions due to increased pressure at work (Nakanome, 2009; Shimizu, 2011).

The limited labor supply is causing the same negative consequence of 'karoshi', or death by overwork, as that which resulted from Japanese companies cutting their payroll and increasing employee workload following the oil crisis in the 1970s (ILO, 1993). Ishida (2002) extensively reviewed the socio-medical origins of karoshi and its evolution towards general labor and welfare discussions. The word karoshi itself was coined by Dr. Tetsunojo Uehata to describe a "condition in which physiologically unsound work processes are allowed to continue in a way that disrupts the worker's normal work and life rhythms, leading to a build-up of fatigue in the body and a chronic condition of overwork accompanied by a worsening of pre-existent high blood pressure and a hardening of the arteries, finally resulting in a fatal breakdown” (Brown et al., 1994, p. 59). Karoshi was again in the news as the suicide of an overworked employee at Dentsu, the giant Japanese advertising agency, caused the ousting of the company CEO and the tightening of Japanese labor legislation (Huang and Stapczynski, 2016). Besides the growing realization that well-being is critical to retain employees, lifetime employment and seniority-based promotion are no longer the two pillars that allow Japanese companies to attract new employees or retain existing employees. The usefulness of lifetime employment has been questioned (Shimoda, 2016), and both lifetime employment and seniority-based promotion have been largely confined to large companies (Babcock, 1996).

Meanwhile, another instrument leading potentially to higher performance and to higher employee retention - well-being - has emerged in recent research. Hence, clarifying the antecedents of wellbeing is important for companies in Japan to remain attractive by substituting well-being to declining lifetime employment and seniority-based promotion. Well-being has been linked to important consequences in the workplace, such as productivity, job performance, retention, sociability, and 
physical health (Lyubomirsky et al., 2005; Judge et al., 2001; Amstad et al., 2011).

Therefore, Japanese companies must rethink their work practices, mind job satisfaction, and consider the well-being of their employees, if they want to reduce labor turnover and attract new recruits, Japanese or foreign. In doing so, Japanese firms should examine job task characteristics and how these affect job satisfaction and well-being. While job satisfaction has been a common concern among companies (Spector, 1997), well-being at work has started more recently to get some corporate attention (Great Place to Work, 2015). However, such research in Japanese businesses remains scarce (Diener et al., 1995, Spector; 1997) although Japanese employees have displayed comparatively lower job satisfaction in cross-national research (Sousa-Poza and Sousa-Poza, 2000).

At the same time, while the link between certain job task characteristics, job satisfaction, and wellbeing has already been established in some past research (Hackman and Oldham, 1980; Warr, 1987; Wall et .al, 1990; Kelloway and Barling, 1991; Ilardi et al., 1993; Morgeson and Humphrey, 2006), the literature about Japanese companies remains scarce. This paper attempts to fill the research gap on the relationships between job task characteristics, job satisfaction, and subjective well-being among Japanese employees. The next section reviews past literature on these concepts, followed by the research model and methodology, analysis, discussion, and conclusion.

\section{Literature Review and Hypotheses Development}

\subsection{Subjective Well-being}

The importance of subjective well-being in the workplace has been underscored by showing its positive influence on productivity and job performance (Lyubomirsky et al., 2005; Judge et al., 2001). Happiness is a concept often used to describe the psychological state of contentment or joy, and in research, it is operationalized as well-being or subjective well-being. According to Ryan and Deci (2001), "well-being refers to optimal psychological functioning and experience" (p. 142), and that concept is usually defined from the two approaches of hedonic and eudaimonic perspectives. The hedonic approach equates well-being with the pursuit of hedonic pleasure or happiness whereby subjective well-being "concerns the experience of pleasure versus displeasure broadly construed to include all judgments about the good/bad elements of life" (p. 144). The eudaimonic view considers well-being to be different from happiness because some desires and the pleasures derived from their fulfillment may not lead to well-being (Ryan \& Deci, 2001).

Subjective well-being denotes an overall evaluation of a good or satisfactory state of existence. It 
is a global measure of how well one is faring in life. Diener et al. (1999) define subjective well-being as "a broad category of phenomena that includes people's emotional responses, domain satisfactions, and global judgments of life satisfaction" (p. 277). As any self-evaluation of a life must be measured against an individual's values, personalities, goals and beliefs, it is highly subjective. For this reason, many researchers in this area prefer the term subjective well-being when discussing appraisement of a person's life (Diener et al., 2003).

The primary measure of subjective well-being is separated between the assessment of emotions and that of life in general (Helliwell et al., 2015). The first element concerns emotions, both positive and negative, towards daily events; the second, one's evaluation of life as a whole, which can be said to be more fully explained by enduring life circumstances such as one's family, social or work relationships and environment. The first component of emotions reflects responses to shorter-term circumstances or exchanges that occur daily, for example being recognized for a job well done, or alternatively being reprimanded for poor performance. The second component is multi-faceted and is influenced by all the different areas of one's life.

These two components for measuring subjective well-being can capture the variations in emotions one might experience in life and the overall sense of how one evaluates one's life. This assessment of one's own subjective well-being using positive affect, negative affect, and satisfaction in life is consistent with Seo et al. (2015)'s recommendation. Feelings of energy and engagement, and of distress and anxiety, can be found as instances of positive affect and negative affect in the literature (Olesen et al., 2015).

Because hours spent at work make up a good portion of one's life, satisfaction with one's job has the potential to significantly affect subjective well-being. The role of job satisfaction on subjective well-being has already been highlighted by Ryan and Deci (2001).

\subsection{Job Satisfaction}

Job satisfaction started garnering attention in the 1920s when research by Elton Mayo on working conditions at the Hawthorne Works in Illinois (USA) highlighted the relationship between job task characteristics and job satisfaction, which both positively affected job productivity (Mayo, 1945). Job satisfaction, or feelings of satisfaction with one's job and on the job, is important as it has been found to act as a job motivator (Mottaz, 1985; Colarelli et al., 1987; Brief \& Weiss, 2002). Locke (1969) defines it as "the pleasurable emotional state resulting from the appraisal of one's job as achieving or facilitating the achievement of one's job values" (p. 316) and later added to that prior definition the “appraisal of one's job or job experiences" (1976, p. 1304). Locke (1969) further specifies that 
"overall job satisfaction is the sum of the evaluations of the discriminable elements of which the job is composed" (p. 330) and that typically, measurements include questions for each specific job elements whose results are then added with possibly the use of weights based on the importance of the constitutive elements. In broader terms, job satisfaction measures "the degree to which workers are happy with their job and daily work life" (Yamaguchi, 2013, p. 60).

Satisfaction is usually considered from the perspectives of needs, defined as "a person's conscious wants, desires, or motives" and which are viewed as individual constructs (Baard et al., 2004, p. 2046). These needs have been used to predict work-related outcomes such as job satisfaction (Hackman \& Lawler, 1971). In the study of the satisfaction of needs, the self-determination theory focused on the three individual innate and psychological needs for competence, autonomy, and relatedness (Deci \& Ryan, 1985; Ryan \& Deci, 2000). According to that theory, individuals are self-determining and intrinsically motivated to continue working in their current job. The need for competence is about "succeeding at optimally challenging tasks and being able to attain desired outcomes" (Baard et al., 2004, p. 2046). The satisfaction of this need to master challenging tasks can make use of and develop one's skills. The need for autonomy is related to "experiencing choice and feeling like the initiator of one's own actions" (Baard et al., 2004, p. 2046). The satisfaction of this need is less about the autonomy in performing a task rather than experiencing psychological freedom (Broeck et al., 2010). Last, the need for relatedness is concerned with "establishing a sense of mutual respect and reliance with others" (Baard et al., 2004, p. 2046). The satisfaction of this need is related to feelings of connection to others and membership to a group which provides support (Broeck et al., 2010). According to the self-determination theory, these three needs must be satisfied continuously for people to function and perform.

Basic psychological needs have been separated in different categories, such as general needs and those in specific areas. The work-related basic need satisfaction scale has been used in most prior research assessing job satisfaction in a work context (Kasser et al., 1992; Ilardi, Leone, Kasser, \& Ryan, 1993; Baard et al., 2004) and it has recently received additional validation as a robust scale (Broeck et al., 2010).

The fulfillment of these needs can be affected by careful design of job characteristics; indeed, Hackman and Oldham (1976) found that job task characteristics affect job satisfaction.

\subsection{Job Task Characteristics}

Task characteristics are a subset of motivational work characteristics, on par with knowledge, social, and contextual characteristics. In a comprehensive review of the literature, Morgeson and Humphrey 
(2006) assert that, among motivational work characteristics, task characteristics have been the most commonly examined and those cover how the work is carried out and the nature of the tasks included in a particular job. In this research, we specifically focus on these task characteristics only because other characteristics are inherently more subjective and answers may vary based on various respondent attributes unrelated to their task.

The five core task characteristics consist of autonomy, task variety, task significance, task identity, and feedback from job (Hackman and Oldham, 1974, 1976, 1980). These task characteristics have been found to affect a number of job-related outcomes, including work motivation and job satisfaction (Hackman and Oldham, 1974, 1980; Morgeson and Humphrey, 2006). The resulting job satisfaction is all the more important as it is thought to act as an incentive for the employee to continue in the accomplishment of its task, thus supporting organizational effectiveness.

Autonomy. "The degree to which the job provides substantial freedom, independence, and discretion of the employee in scheduling the work and in determining the procedures to be used in carrying it out" (Hackman and Oldham, 1974, p. 9). Autonomy includes the employee's freedom in work scheduling, decision-making, and work methods (Morgeson and Humphrey, 2006).

Task Variety. Hackman and Oldham (1974, p. 9) initially focused on skill variety, which they defined as "The degree to which a job requires a variety of different activities in carrying out the work, which involve the use of a number of different skills and talents of the employee". Subsequent research expanded the construct to include several tasks, rather than skills, and is therefore described as the degree to which a job requires employees to perform a wide range of tasks on the job (Morgeson and Humphrey, 2006). This shift in focus from skill to task highlights the importance of non-routine tasks calling for a variety of skills.

Task Significance. "The degree to which the job has a substantial impact on the lives or work of other people - whether in the immediate organization or in the external environment" (Hackman and Oldham, 1974, p. 9). Task significance plays a role in how the employee perceived the impact of its work and has been found to enhance the employee's feeling of being valued by the organization and the stakeholders who benefit from its work (Grant, 2008).

Task Identity. "The degree to which the job requires completion of a 'whole' and identifiable piece of work, i.e., doing a job from beginning to end with a visible outcome" (Hackman and Oldham, 1974, p. 9). An employee who performs a task with clear boundaries and evaluable deliverables, such as a complete service or product, is more satisfying and motivating than piecemeal tasks whose relation to the final outcome is difficult to fathom (Hackman \& Oldham, 1980). 
Feedback from the Job Itself. "The degree to which carrying out the work activities required by the job results in the employee obtaining direct and clear information about the effectiveness of his or her performance" (Hackman and Oldham, 1974, p. 9). This feedback from the job itself is different from that from others, as it relates to the knowledge created by the employee while or after having performed the job rather than from interactions with co-workers or its manager (Hackman \& Oldham, 1980).

\subsection{Hypotheses Development}

The relationships between these constructs have been widely researched and supported in the past literature, as discussed below. Because the goal of this paper is to examine whether job satisfaction mediates the relationship between job task characteristics and subjective well-being in the Japanese context, we first decompose the mediation into three relationships and test the resulting model.

Japanese employees work long hours and take very little time off. McCurry (2015), looking at Japanese government data, notes that about $22 \%$ of Japanese employees work more than 49 hours a week, compared with $16 \%$ of US workers and 11\% in France and Germany, and that most Japanese workers only use nine of their 18.5 days' average entitlement of paid holidays. The reasons stated by Japanese workers for such long hours and so little time off include extreme fluctuation in work amount and frequently arising sudden and unforeseen duties, insufficient number of staff, producing products/results of satisfactory quality, nature of the work or customer demands, and unevenly distributed work among employees (Japanese Ministry of Health, Labor and Welfare, 2015).

According to a recent survey by the British-based Chartered Institute for Personnel and Development (CIPD), Japanese workers, tied with French workers, rank last in job satisfaction among G8 countries (Chartered Institute for Personnel and Development, 2013). Furthermore, younger Japanese employees (under 30) report the lowest job satisfaction and highest job dissatisfaction among South Korea, Japan, the US, the UK, Germany, France, and Sweden, as noted by an international survey conducted by the Japanese Cabinet Office in 2013 (Japanese Cabinet Office, 2013).

These unique conditions of the Japanese work environment call for examining previous results which were found to link job task characteristics, job satisfaction, and subjective well-being.

\subsubsection{Job task characteristics and job satisfaction}

Job satisfaction is usually considered in terms of its situational job antecedents, which can be broadly traced to the works of Herzberg et al. (1956)'s motivation-hygiene theory, of Hackman and 
Oldham (1976)'s job task characteristics model, and of Warr (2007)'s comprehensive review of the literature. Herzberg et al. (1956) were the first to underline and categorize the antecedents of job satisfaction in two categories: real motivational factors (achievement, recognition, work, responsibility, promotion, and growth) which positively affect job satisfaction but have no effect on job dissatisfaction, and hygiene factors (pay, company policy, good relationships with co-workers, and supervision) which negatively influence job dissatisfaction but have no effect on job satisfaction. Later, Hackman and Oldham (1976) proposed and tested their job task characteristics model and found that their five job task characteristics affected job satisfaction, "especially satisfaction with opportunities for personal growth and development on the job" (p. 259). As stated before, these job task characteristics have been found to affect a number of job-related outcomes, including work motivation and job satisfaction (Hackman and Oldham, 1974, 1980; Morgeson and Humphrey, 2006). More recently, Morgeson and Humphrey (2006) and Warr (2007) developed comprehensive models of job task characteristics, building on Hackman and Oldham (1976)'s original model, which proved to positively affect job satisfaction. Therefore, we hypothesize the following:

Hypothesis 1: The five job task characteristics of autonomy, task variety, task significance, task identity, and feedback from job (Hackman and Oldham, 1974, 1976, 1980) positively affect job satisfaction (H1).

\subsubsection{Job satisfaction and subjective well-being}

The link between job satisfaction and subjective well-being has been intensively examined and debated (Unanue et al., 2018). Unanue et al. (2018) reviewed the three main conceptualization of that relationship, namely the segmentation, compensation, and spillover hypotheses. The segmentation hypothesis argues that there is no relationship between job satisfaction and life satisfaction, the compensation hypothesis that people compensate for their job dissatisfaction by finding more satisfaction in other areas of their life, and the spillover hypothesis that there is a positive relationship between job satisfaction and life satisfaction (for a review, see Rain et al., 1991). We implicitly adopted the spillover hypothesis, which is the most supported in the literature, and which posits that "there is a positive relationship between job satisfaction and life satisfaction" (Unanue et al., 2018, p. 2 ). As for the directionality of the relationship, different results have supported both opposite causal links (Heller et al., 2002; Judge et al., 2001) as well as bi-directional associations (Rode, 2004).

Ryan and Deci (2001) argue that the self-determination theory "posits that satisfaction of the basic psychological needs typically fosters subjective well-being as well as eudaimonic well-being" (p. 147). They explain that satisfaction with one's life, along with more positive affect and less negative 
affect, indicate psychological wellness or subjective well-being. Similarly, Baard et al. (2004) found that intrinsic need satisfaction on the job predicts both performance ratings and psychological wellbeing of employees. Therefore, we hypothesize the following:

Hypothesis 2: Job satisfaction positively affects subjective well-being (H2).

Hypotheses 1 and 2 imply a mediating role of job satisfaction in the relationship between job task characteristics and subjective well-being.

\subsubsection{Job task characteristics and subjective well-being}

Last, the impact of work on individual well-being has been widely supported by past psychological research (Warr, 1987; Kelloway and Barling, 1991). More precisely, job task characteristics and job redesign have been shown to affect psychological well-being and mental health in general (Wall et al., 1978, 1990). Therefore, we hypothesize the following:

Hypothesis 3: Job task characteristics positively affect subjective well-being (H3).

The three hypotheses combine into a model whereby job satisfaction mediates the relationship between job task characteristics and subjective well-being (Figure 1).

Insert Figure 1 about here

\section{Method}

\subsection{Sample and Measures}

To test the hypotheses presented above, a questionnaire survey of salaried managers and staff, all Japanese, working in Japan for Japanese domestic companies in a wide range of industries was conducted. The survey instrument was first built in English, and then translated and administered in Japanese by the authors who are fluent in both languages. The data was gathered in March 2015 using a Japanese Internet Survey service with a large database of potential respondents throughout Japan. Respondents were selected among Japanese employees working in Japan. Respondents numbered 208 , consisted of $75 \%$ male and $25 \%$ female respondents from a wide range of industries and working in different functions, and were split evenly between those employed as general staff with no supervisory duties (104) and managers with subordinates (104) (Table 1). The internet survey firm sent out the questionnaire to respondents, continuously monitoring the sample composition and closing the survey as soon as composition requirements were satisfied. 
Insert Table 1 about here

For job task characteristics, following Morgeson and Humphrey (2006)'s Work Design Questionnaire, 24 questions were used to evaluate the respondents' perceptions of their task characteristics, and specifically autonomy, task variety, task significance, task identity, and feedback from job. For subjective well-being, as emotions tend to fluctuate as a person interacts and reacts to different exchanges and events throughout the day, Helliwell et al. (2015) propose to use measures which address positive and negative emotions. And the Organization for Economic Cooperation and Development, in its guidelines on measuring subjective well-being, recommends including a question on overall life satisfaction (OECD, 2013). We therefore use a general question about the respondents' overall life satisfaction, two questions about positive emotions, and three about negative emotions. Last, for job satisfaction, we use Deci and Ryan (2000)'s Basic Psychological Needs Scale at Work covering in 21 items the three needs for competence, autonomy, and relatedness. All questions were asked on a 5-point Likert scale.

In addition to demographic questions (gender, age), the questionnaire included items inquiring into the respondent's situation with the present company (number of years at the company, position, function), the characteristics of the company (size at the location where the respondent works, in the subsidiary including the aforementioned location, in Japan as a whole, and industry). Indeed, demographics could influence the variables under study, as for instance, the content and nature of work, i.e. task characteristics, are affected in part in the Japanese context by gender, age, seniority, and position (Loscocco and Roschelle, 1991). While the management style of Japanese companies is changing, shifting from a seniority-based system to a performance-based one (Miyamoto, 2009), seniority-based promotion is still prevalent and differentiated career tracks exist for male and female workers in many organizations.

The pool of respondents is $75 \%$ male with a majority of people in their 30 s and $40 \mathrm{~s}$, half has subordinates, a third work at companies with less than 10 employees, and a relative majority is engaged in the manufacturing sector.

\subsection{Validity and Reliability}

Factor analyses were conducted with each subset of questions pertaining to each variable - task characteristics, job satisfaction, and well-being - to ensure that the questions displayed highest loadings on the intended constructs and to assess discriminant validity. Following Costello and 
Osborne (2005)'s recommendations, question items with excessive cross-loadings, freestanding as one-item factors, or considerably reducing factor reliability were removed. Marked differences were found between the intended constructs and those obtained with the current sample. All factors were found to be reliable with Cronbach alpha scores near or above 0.7 .

For job task characteristics, three factors with eigenvalues above one were generated rather than the intended five factors; the factors obtained indicated the dimensions of job autonomy \& task identity, job skill variety, and job task significance, suggesting that in this sample job autonomy and task identity items were answered in a similar manner. It is important to note that all questions pertaining to job feedback displayed equal loading on the factors related to job autonomy \& task identity and to job skill variety, and therefore there were removed from the subsequent analysis (Costello and Osborne, 2005). These factors explained 36\%, 18\%, and $12 \%$ of the total variance respectively, for a total of $65 \%$. For subjective well-being, two factors with eigenvalues above 1 were obtained, the first one related to positive subjective well-being and explaining $39 \%$ of the total variance, and the second one to negative subjective well-being and explaining $33 \%$ of the total variance, for a combined total of $73 \%$. For job satisfaction, three factors with eigenvalues above 1 were achieved, the first one consistent with relatedness and explaining $35 \%$ of the total variance, the second one indicating self-accomplishment and explaining $19 \%$ of the total variance, and the last one denoting competence and explaining $12 \%$ of the total variance, for a combined total variance explained of $66 \%$. These factors differed from the original constructs in that the autonomy-related job satisfaction is replaced by self-accomplishment job satisfaction.

\section{Analysis}

\subsection{Descriptive Statistics}

In order to examine significant differences among the constructs and compare them on a 5-point Likert scale, mean scores were calculated for each dimension. Overall, the means of job task characteristics, job satisfaction, and positive well-being were found to be above 3.0, except for job satisfaction-competence (2.9). Table 2 shows the means, standard deviations, and correlations. In terms of gender, female respondents, compared to male respondents, were found to work in offices with fewer employees. Position related positively to all three task characteristics, especially autonomy $\&$ task identity, to self-accomplishment and relatedness-related job satisfaction, and to positive wellbeing. 
Insert Table 2 about here

Several statistically significant differences, using one-way ANOVA, were found by comparing the constructs under study with demographic data. Regarding gender, female respondents, compared to male respondents, reported stronger relatedness-related job satisfaction (mean of 3.5 versus 3.3; $\mathrm{F}(1,206)=6.538, \mathrm{p}=0.011$ ) and higher positive subjective well-being (mean of 3.3 versus 3.0; $\mathrm{F}(1,206)=4.776, \mathrm{p}=0.030$ ). This result is consistent with Genda (2016)'s findings who reported that females in Japan are generally happier than males.

Concerning the size of the companies where the respondents worked, it affected the respondents' job satisfaction-relatedness and job satisfaction-self-accomplishment $(F(4,203)=3.337, p=0.011$; $\mathrm{F}(4,203)=2.515, \mathrm{p}=0.043$ ) (Figure 2). Lower levels were reported for those in mid-size companies (over 10 and below 499 employees), and higher levels for those in very small companies (less than 10 employees) and large organizations (500 employees and over).

Insert Figure 2 about here

\subsection{Model}

The following statistical tests use SPSS and PROCESS, a freely available computational tool for SPSS that specifically addresses mediation, moderation, or conditional process analyses (Hayes, 2012). Although structural equation modeling (SEM) may offer greater flexibility for model specification, it is best reserved for very complex models since it requires more effort for similar results. Based on extensive experiments, Hayes et al. (2017) assert that "for models that are based entirely on observed variables, investigators can rest assured that it generally makes no difference which is used, as the results will be substantively identical" and that "the choice, in that case, is inconsequential" (pp. 80-81).

We assessed the effect of task characteristics on subjective well-being both directly and indirectly through the respondents' levels of job satisfaction. This corresponds to the model depicted in Figure 3 , which estimates an unmoderated mediation model. Because the previous factor analysis revealed three components for task characteristics in our sample, three separate mediation analyses were conducted each time with one of the three task characteristics as independent variable (Tables 3, 4, 
and 5).

Insert Figure 3 about here

Insert Tables 3, 4, 5 about here

For job autonomy $\&$ task identity, the total effect is statistically significant $(0.253, \mathrm{p}<0.001)$, while the direct effect is not, indicating that higher job autonomy \& task identity does not directly result in higher positive well-being. Only the indirect effects through self-accomplishment- and relatednessrelated job satisfaction are statistically significant ( 0.083 and 0.149 , respectively). It is important to note that the significance of indirect effects is not assessed based on the statistical significance of the paths that define them but rather on asymmetric bootstrap confidence intervals which are entirely above zero ( 0.035 to 0.156 and 0.074 to 0.262 , respectively) (Hayes, 2012). The normal theory-based Sobel tests $(Z=2.981, p<0.05$ and $Z=4.261, p<0.001$, respectively) agree with the inferences made using a bias-corrected bootstrap confidence interval (Hayes, 2012). These findings indicate that the impact of job autonomy \& task identity on positive well-being is fully mediated by selfaccomplishment- and relatedness-related job satisfaction, thus providing partial support for $\mathrm{H} 1$ and $\mathrm{H} 2$, and disproving $\mathrm{H} 3$.

For job skill variety, the total effect is statistically significant $(0.190, p<0.05)$, while the direct effect is not, suggesting that higher job skill variety is not a source of higher positive well-being. Only the indirect effect through job satisfaction-self-accomplishment is statistically significant $(0.109$; asymmetric bootstrap confidence interval: 0.047 to 0.192 ; normal theory-based Sobel test: $Z=3.622$, $\mathrm{p}<0.001$ ) (Hayes, 2012). This result reveals that the impact of job skill variety on positive well-being is fully mediated by self-accomplishment-related job satisfaction, thus providing partial support for $\mathrm{H} 1$ and $\mathrm{H} 2$, and refuting $\mathrm{H} 3$.

For job task significance, neither total nor direct effects are statistically significant, indicating that higher job task significance is not a source of higher positive well-being. Only the indirect effect through job satisfaction-self-accomplishment is statistically significant $(0.101$; asymmetric bootstrap confidence interval: 0.020 to 0.190 ; normal theory-based Sobel test: $Z=3.3322, p<0.001$ ) (Hayes, 2012). This result suggests that the impact of job task significance on positive well-being is fully 
mediated by self-accomplishment-related job satisfaction, thus providing partial support for $\mathrm{H} 1$ and $\mathrm{H} 2$, and invalidating $\mathrm{H} 3$. The results for the three unmoderated mediation models are summarized in Figure 4.

Insert Figure 4 about here

It is important to note that in this sample, task characteristics do not affect job satisfaction-competence, and furthermore, job satisfaction-competence is not mediating the relationship between task characteristics and positive well-being.

\section{Discussion and Conclusion}

\subsection{Main Findings and Implications}

Overall, the Japanese workers in the sample evaluate their job task characteristics, job satisfaction, and subjective well-being as slightly higher than average but only moderately high, since those mean scores all fall between 2.99 and 3.58. On the 5-point Likert scale, a score of 3 is neutral and a score of 4 denotes moderate agreement. Of all the constructs, respondents rated job autonomy \& task identity the highest and job satisfaction-competence the lowest. The lower job satisfactioncompetence is consistent with previous research, which indicated a modesty bias among Japanese workers in their core self-evaluation (Judge et al., 1998; Piccolo et al., 2005).

\subsubsection{Constructs}

Regarding task characteristics, the three factors of job autonomy \& task identity, job skill variety, and job task significance were identified, instead of the original four defined in the literature (minus job feedback whose question items were removed because of excessive cross-loading), suggesting that respondents answered job autonomy and task identity items in a similar manner. Indeed, questions assessing job autonomy, or one's discretion in conducting one's work, and task identity, or a task with clear boundaries and evaluable deliverables, all relate to the respondents taking ownership of their specific job. High task identity can be construed as a pre-condition for job autonomy since employees must be able to clearly identify their own tasks in order to take ownership of them.

The shift towards a performance-based system is likely to affect job design and related job task characteristics. A key principle of performance-based management is the assignment of clear and 
identifiable tasks and performance expectations to specific individuals (Moynihan, 2008). The relatively higher rating of job autonomy \& task identity (Table 2) suggests that Japanese workers acknowledge the performance-based nature of their employment system, although this data set does not allow to comment on the potential evolution of their assessment.

The U-shaped curve of job satisfaction-relatedness and job satisfaction-self-accomplishment across company size at the location where respondents are working suggests that those working in small and larger companies feel more closely connected to others at work and more accomplished in their job. In small offices, employees work in a family-type environment, get to know each other well, and have to be polyvalent across a number of tasks, thus creating a sense of accomplishment. In large offices, self-accomplishment may come from the sheer size of the organization and the fact that task delegation has been promoted through strong training and mature business practices. Likewise, in these larger structured organizations, employees can relate first to the name of their organization, and second they can develop feelings of relatedness to their own division or department. In contrast, employees at medium-sized locations were found to have lower levels of job satisfaction-relatedness and -self-accomplishment; we can infer that in organizations with 50 to 249 employees, organizational size may be small enough to be monitored closely, which does not support their own sense of accomplishment, yet large enough for employees to feel somewhat detached from their colleagues. However, little academic research in Japan differentiates small from mid-sized companies, so it is difficult to establish whether this finding supports or contradicts past results.

\subsubsection{Model}

The first major finding of this survey is that there is no direct link between any job task characteristic and positive well-being. This implies that task characteristics alone do not support positive well-being, although they have been shown to be motivating job factors (Hackman and Oldham, 1976, 1980). In other words, companies cannot rely only on job design to directly foster employee well-being, but must ensure that task characteristics translate into work-related outcomes, such as job satisfaction.

But then which type of job satisfaction matters most? According to our results, job satisfactionself-accomplishment was the only mediator between all three job task characteristics and positive well-being. However, job satisfaction-relatedness was the strongest mediator between job autonomy $\&$ task identity and positive well-being. This first indicates that employees' tasks must be designed in such a way that workers can gain a sense of achievement. Second, companies must ensure that their employees have sufficient work autonomy and identifiable tasks to elicit job satisfaction-relatedness. 
Employees who enjoy more freedom with less fragmented tasks accomplish their work on their own and are free to develop personal relationships at the office. We can infer here that greater job autonomy \& task identity fosters a higher degree of relatedness, which consists of both mutual respect and support, maybe because autonomy and identifiable tasks enable personal recognition among employees. While working in teams has clear benefits for creativity, it can cause contention and social stress in the organization and may not be appropriate for tasks that can be successfully accomplished by lone employees. This is somewhat in contradiction with previous research which found that jobs with high task identity increased accountability and therefore stress (Hochwarter et al., 2005).

In the Japanese context, higher task identity which requires employees to complete a whole and identifiable output translates into higher job satisfaction-relatedness and -self-accomplishment. Indeed, one of the characteristics of the Japanese intellectual tradition is "oneness of self and others" (Nonaka and Takeuchi, 1995, p. 27). Past scholars have shown that this trait extends to Japanese organizations, which can be understood as organic entities, stressing human relationships over functional relationships, favoring harmony, networking, and socialization (Judge, Erez, \& Bono, 1998).

What's more, the strong association between job autonomy \& task identity and relatedness-related job satisfaction extends our understanding of the antecedents of job satisfaction for Japanese workers. For instance, recent results by Drabe et al. (2015) indicated that the situational antecedents of job satisfaction for Japanese workers consisted of having good relationships with colleagues and management, an interesting job, and to a lesser extent independent work, but not job autonomy or task identity. Organizations in Japan, which ensure that they create an environment where employees feel at ease with one another, emphasizing cooperation over competition, can therefore maximize the link between job task characteristics and well-being.

This highlights a growing challenge since some Japanese corporations have been shifting from a seniority-based system to a performance-based one (Miyamoto, 2009), breaking the predictability of the seniority-based promotion system Japanese workers have come to expect. Since the bubble burst more than 25 years ago, job satisfaction has been decreasing while working hours continue to be long. Thus, Japanese firms must focus on improving subjective well-being by understanding its antecedents, such as job task characteristics and job satisfaction. Due to a very tight labor supply and attractive conditions at Japan-based foreign firms, the sources of job satisfaction may not only be evolving, but Japanese employers need to adapt to attract and retain employees.

Another major finding of this survey is to have revealed the centrality of the relatedness component 
(among the job satisfaction components) in the relationship between task characteristics and positive well-being in Japan. While self-determination theory (Deci \& Ryan, 1985; Ryan \& Deci, 2000) contends that people from all cultures share basic psychological needs for autonomy, competence, and relatedness, our research underscores the centrality of relatedness in the context of the Japanese workplace. Our results reveal that relatedness is, among all job satisfaction factors, a core conduit between job design and positive well-being. Figure 4 illustrates the weight of relatedness both in the relationship between job design and job satisfaction and in the relationship between job satisfaction and positive well-being. Dennis et al. (2002) have showed that from a very young age, Japanese more than Americans, are encouraged to emphasize shared rather than individual experiences. The strong relationship between relatedness and well-being found in the Japanese sample is consistent with Kitayama and Markus (2000)'s assertion that in East Asian cultures happiness stems from "engaging the sympathy of others" (pp. 113-114).

Cultures that value fitting in or belonging, such as the Japanese one, support interdependent (conjoint) agency (Markus \& Kitayama, 2003), a form of agency originating and promoting connectedness with significant others; interdependent agency differs from European and American independent (disjoint) agencies, which emphasize "an autonomous self that is different and separate from others" (Güngör et al., 2014, p. 1375). While Güngör et al. (2014) have already hinted at the relationship between autonomy and well-being for the Japanese by showing that autonomy is not only important for the Japanese, but that it also predicts their personal well-being, we have enhanced the comprehension of this relationship by adding the pivotal and mediating effect of relatedness. The first aspect of this centrality is the relationship between job autonomy and relatedness. According to selfdetermination theory, people feel autonomous when they behave in a way congruent with their true interests or integrated values and desires (Deci \& Ryan, 1985). Hence, "the opposite of autonomy is not dependence but rather heteronomy, in which one's actions are experienced as controlled by forces that are phenomenally alien to the self" (Chirkov et al., 2003, p. 98). Hence, consensus-building and participatory work structures, typical of the Japanese workplace culture, shape organizational commitment and work satisfaction (Lincoln \& Kalleberg, 1985).

How do these findings fit with the well-documented long hours worked and the few vacations days taken by Japanese workers? Recent research has highlighted the moderating role of job satisfaction: long working hours are associated with increased risk of depressive symptoms (precursors of 'karoshi') but only for workers who reported lower job satisfaction (Nakata, 2017). Therefore, the role of job satisfaction, albeit as mediator in our research, is further underscored. 
On the other hand, the model did not show a link between any of the three job task characteristics and job satisfaction-competence. This result implies that none of these three job task characteristics (job autonomy \& task identity, skill variety, and task significance achieving challenging tasks), while all denote a meaningful job, are linked to a satisfactory sense of competence in this sample of Japanese workers. Furthermore, a single significant correlation was found between job satisfaction-competence and job satisfaction-relatedness $(\mathrm{r}=0.16, \mathrm{p}<0.05)$. We can conclude that for Japanese workers, the sense of competence is not predicated on the task itself, but rather on the relationships with others. Trompenaars and Hampden-Turner (2012) have convincingly showed that the Japanese are both communitarian and outer-directed, meaning that the community comes before the individual and that at work, they focus their actions on others, avoiding conflicts and needing reassurance about the quality of their work. In other words, their competence self-evaluation comes from their relationships within the group.

Additionally, while previous research showed relationships between job design and job satisfaction (Hackman and Oldham, 1976, 1980; Morgeson and Humphrey, 2006; Warr, 2007), and between job satisfaction and well-being (Ilardi et al., 1993; Deci et al., 2001; Baard et al., 2004), there had not been a study investigating the links between all three. Our findings suggest that job satisfaction plays a central role in the relationship between job design and well-being. Also, research on Japanese wellbeing at work is scarce and this study indicates that in Japanese firms at least, job satisfaction-selfaccomplishment and -relatedness strongly affect subjective well-being. In particular, job-satisfactionrelatedness was shown to have the strongest effect on subjective well-being, which is not surprising considering the importance Japanese culture places on harmony and belongingness (Oikawa and Tanner, 1992). These findings suggest that for Japanese employees, careful attention to job design is necessary, but not sufficient, for promoting subjective well-being, and that firms should evaluate how job design affects job-related outcomes.

\subsection{Limitations}

This study evaluates job design, job satisfaction, and subjective well-being using constructs derived from research conducted in the United States. Different core dimensions for Japanese workers can thus be expected. The paucity of research and the absence of native scales in Japan call for the identification of country-specific dimensions. Factor analyses were conducted to develop and validate constructs for the Japanese sample, and these adapted constructs are a starting point for future research. This will enable the development of a more culture-specific theoretical framework and pragmatic suggestions for Japanese firms. 
The sample is both relatively small in size and cross-sectional, which limits the generalizability of the findings. While the collected data includes a diversity of respondents in terms of positions and functions, and in terms of company sizes and industries, future research should focus on specific businesses or activities, or particular job roles, in order to identify relevant job task characteristics and dimensions of job satisfaction. It would be of particular interest for instance to compare job design, job satisfaction, and subjective well-being between regular and non-regular employees. Last, data for dependent and independent variables were collected simultaneously in the same survey instrument, raising the risk of common method variance. To eliminate such risk, future research will collect the same data separately.

\section{References}

Amstad, F., Meier, L., Fasel, U., Elfering, A., \& Semmer, N. (2011). A meta-analysis of workfamily conflict and various outcomes with a special emphasis on cross-domain versus matchingdomain relations. Journal of Occupational Health Psychology, 16(2), 151-169.

Baard, P., Deci, E., \& Ryan, R. (2004). Intrinsic Need Satisfaction: A Motivational Basis of Performance and Weil-Being in Two Work Settings. Journal of Applied Social Psychology, 34(10), 2045-2068.

Babcock, D.L. (1996). Managing engineering and technology. New York, NY: Prentice Hall.

Brief, A. P. \& Weiss, H. M. (2002). Organizational behavior: Affect in the workplace. Annual Review of Psychology, 53(1), 279-307.

Broeck, A., Vansteenkiste, M., Witte, H., Soenens, B., \& Lens, W. (2010). Capturing autonomy, competence, and relatedness at work: Construction and initial validation of the Work-related Basic Need Satisfaction scale. Journal of Occupational and Organizational Psychology, 83(4), 981-1002.

Brown, W., Lubove, R., \& Kwalwasser, J. (1994). Karoshi: Alternative perspectives of Japanese management styles. Business Horizons, 37(2), 58-60.

Chartered Institute for Personnel and Development (2013). The way the world works. Available at: http://www.cipd.co.uk/NR/rdonlyres/1ED3CECE-77BF-4548-89AFA5B766D3ED7B/0/CIPD_G8_INFOGRAPHIC.pdf

Chirkov, V., Ryan, R. M., Kim, Y., \& Kaplan, U. (2003). Differentiating autonomy from individualism and independence: A self-determination theory perspective on internalization of 
cultural orientations and well-being. Journal of Personality and Social Psychology, 84(1), 97-110.

Colarelli, S., Dean, R., \& Konstans, C. (1987). Comparative effects of personal and situational influences on job outcomes of new professionals. Journal of Applied Psychology, 72(4), 558-566.

Costello, A. B., \& Osborne, J. W. (2005). Best practices in exploratory factor analysis: Four recommendations for getting the most from your analysis. Practical Assessment, Research \& Evaluation, 10, 1-9.

Deci, E. \& Ryan, R. (2000). The "What" and "Why" of Goal Pursuits: Human Needs and the SelfDetermination of Behavior. Psychological Inquiry, 11(4), 227-268.

Deci, E., \& Ryan, R. (1985). Intrinsic motivation and self-determination in human behavior. New York: Plenum.

Deci, E., Ryan, R., Gagne, M., Leone, D., Usunov, J., \& Kornazheva, B. (2001). Need Satisfaction, Motivation, and Well-Being in the Work Organizations of a Former Eastern Bloc Country: A CrossCultural Study of Self-Determination. Personality and Social Psychology Bulletin, 27(8), 930-942.

Dennis, T. A., Cole, P. M., Zahn-Waxler, C., \& Mizuta, I. (2002). Self in context: Autonomy and relatedness in Japanese and US mother-preschooler dyads. Child Development, 73(6), 1803-1817.

Diener, E., Diener, M., \& Diener, C. (1995). Factors predicting the subjective well-being of nations. Journal of Personality and Social Psychology, 69(5), 851-864.

Diener, E., Oishi, S., \& Lucas, R. E. (2003). Personality, culture, and subjective well-being: Emotional and cognitive evaluations of life. Annual Review of Psychology, 54, 403-425.

Diener, E., Suh, E., Lucas, R., \& Smith, H. (1999). Subjective well-being: Three decades of progress. Psychological Bulletin, 125(2), 276-302.

Drabe, D., Hauff, S., \& Richter, N. F. (2015). Job satisfaction in aging workforces: An analysis of the USA, Japan and Germany. The International Journal of Human Resource Management, 26(6), 783-805.

Genda, Y. (2016). An international comparison of hope and happiness in Japan, the UK, and the US. Social Science Japan Journal, 19(2), 153-172.

Grant, A. M. (2008). The significance of task significance: Job performance effects, relational mechanisms, and boundary conditions. Journal of Applied Psychology, 93 (1), 108-124.

Great Place to Work (2015). What is a Great Place to Work? Retrieved from: 
http://www.greatplacetowork.com/about-us

Güngör, D., Karasawa, M., Boiger, M., Dinçer, D., \& Mesquita, B. (2014). Fitting in or sticking together: The prevalence and adaptivity of conformity, relatedness, and autonomy in Japan and Turkey. Journal of Cross-Cultural Psychology, 45(9), 1374-1389.

Hackman, J. \& Oldham, G. (1974). The job diagnostic survey: An instrument for the diagnosis of jobs and the evaluation of job redesign projects. Department of Administrative Sciences: Yale University.

Hackman, J., \& Lawler, E. (1971). Employee reactions to job characteristics. Journal of Applied Psychology, 55(3), 259-286.

Hackman, J., \& Oldham, G. (1976). Motivation through the design of work: Test of a theory. Organizational Behavior \& Human Performance, 16, 250-279.

Hackman, J., \& Oldham, G. (1980). Work Redesign. Reading, MA: Addison-Wesley.

Hayes, A. F. (2012). PROCESS: A versatile computational tool for observed variable mediation, moderation, and conditional process modeling [White paper]. Retrieved from http://www.afhayes.com/public/process2012.pdf

Hayes, A. F., Montoya, A. K., \& Rockwood, N. J. (2017). The analysis of mechanisms and their contingencies: PROCESS versus structural equation modeling. Australasian Marketing Journal, 25(1), 76-81.

Heller, D., Judge, T. A., \& Watson, D. (2002). The confounding role of personality and trait affectivity in the relationship between job and life satisfaction. Journal of Organizational Behavior, 23(7), 815-835.

Helliwell, J., Layard, R., \& Sachs, J. (2015). World Happiness Report 2015. Columbia University Earth Institute. Retrieved from: http://worldhappiness.report/download/

Herzberg, F., Mausner, B., \& Snyderman, B. B. (1956). The motivation to work. New York/London: Wiley.

Hochwarter, W. A., Perrewé, P. L., Hall, A. T., \& Ferris, G. R. (2005). Negative affectivity as a moderator of the form and magnitude of the relationship between felt accountability and job tension. Journal of Organizational Behavior, 26(5), 517-534.

Huang, G. \& Stapczynski, S. (2016). Suicide of overworked woman, 24, prompts ad giant Dentsu 
to trim overtime hours. The Japan Times. Retrieved from http://www.japantimes.co.jp/news/2016/10/19/business/suicide-overworked-woman-24-promptsad-giant-dentsu-trim-overtime-hours/

Ilardi, B., Leone, D., Kasser, T., \& Ryan, R. (1993). Employee and Supervisor Ratings of Motivation: Main Effects and Discrepancies Associated with Job Satisfaction and Adjustment in a Factory Setting. Journal of Applied Social Psychology, 23(21), 1789-1805.

ILO (1993). World Labour Report 1993. International Labour Office, Geneva.

Ishida, M. (2002). Death and suicide from overwork: The Japanese workplace and labour law. In J. Conaghan, R. Fischl, \& K. Klare (eds.), Labour law in an era of globalization (1st ed.). Oxford: Oxford University Press.

Japanese Cabinet Office (2013). International Survey of Youth Attitude 2013. Available at: http://www8.cao.go.jp/youth/english/survey/2013/pdf/part2-2.pdf

Japanese Ministry of Health, Labor and Welfare (2015). 2015 White Paper on the Labor Economy. Available at: http:/www.mhlw.go.jp/english/wp/l-economy/2015/summary.pdf

Judge, T. A., Thoresen, C. J., Bono, J. E., \& Patton, G. K. (2001). The job satisfaction-job performance relationship: A qualitative and quantitative review. Psychological bulletin, 127(3), 376.

Judge, T., Erez, A., \& Bono, J. (1998). The Power of Being Positive: The Relation Between Positive Self-Concept and job Performance. Human Performance, 11(2-3), 167-187.

Judge, T., Thoresen, C., Bono, J., \& Patton, G. (2001). The job satisfaction-job performance relationship: A qualitative and quantitative review. Psychological Bulletin, 127(3), 376-407.

Kasser, T., Davey, J., \& Ryan, R. (1992). Motivation and employee-supervisor discrepancies in a psychiatric vocational rehabilitation setting. Rehabilitation Psychology, 37(3), 175-188.

Kelloway, E. \& Barling, J. (1991). Job characteristics, role stress and mental health. Journal Of Occupational Psychology, 64(4), 291-304.

Kitayama, S., \& Markus, H. R. (2000). The pursuit of happiness and the realization of sympathy: Cultural patterns of self, social relations, and well-being. In E. Diener \& E. M. Suh (Eds.), Culture and subjective well-being (pp. 113-161). Cambridge, MA, US: The MIT Press.

Lincoln, J. R., \& Kalleberg, A. L. (1985). Work organization and workforce commitment: A study of plants and employees in the U.S. and Japan. American Sociological Review, 50(6), 738-760. 
Locke, E. (1969). What is job satisfaction? Organizational Behavior and Human Performance, 4(4), 309-336.

Lopez, T., Babin, B., \& Chung, C. (2009). Perceptions of ethical work climate and personorganization fit among retail employees in Japan and the US: A cross-cultural scale validation. Journal of Business Research, 62(6), 594-600.

Loscocco, K. \& Roschelle, A. (1991). Influences on the quality of work and nonwork life: Two decades in review. Journal of Vocational Behavior, 39(2), 182-225.

Lyubomirsky, S., King, L., \& Diener, E. (2005). The benefits of frequent positive affect: Does happiness lead to success? Psychological Bulletin, 131, 803-855.

Markus, H. R., \& Kitayama, S. (2003). Models of agency: Sociocultural diversity in the construction of action. In V. Murphy-Berman \& J. J. Berman (Eds.), Vol. 49 of the Nebraska symposium on motivation. Cross-cultural differences in perspectives on the self (pp. 18-74). Lincoln, NE, US: University of Nebraska Press.

Mayo, E. (1945). The social problems of an industrial civilization. Boston: Division of Research, Graduate School of Business Administration, Harvard University.

McCurry, J. (2015). Clocking off: Japan calls time on long-hours work culture. The Guardian. Retrieved from https://www.theguardian.com/world/2015/feb/22/japan-long-hours-work-cultureoverwork-paid-holiday-law

Miyamoto, M. (2009). Where does the Japanese-style performance-based pay come from? (in Japanese：なぜ日本型成果主義は生まれたのか). Japanese Journal of Labor Studies (日本労働研 究雑誌), 51(4), 30-33.

Morgeson, F. P., \& Humphrey, S. E. (2006). The Work Design Questionnaire (WDQ): Developing and validating a comprehensive measure for assessing job design and the nature of work. Journal of Applied Psychology, 91, 1321-1339.

Mottaz, C. (1985). The relative importance of intrinsic and extrinsic rewards as determinants of work satisfaction. Sociological Quarterly, 26, 365-385.

Moynihan, D. P. (2008). The dynamics of performance management: Constructing information and reform. Georgetown University Press.

Nakanome, J. (2009). それでも成果主義は止められない. Nikkei Business, 05/11/2009. Available at: http://business.nikkeibp.co.jp/article/manage/20090507/193988/?rt=nocnt 
Nakata, A. (2017). Long working hours, job satisfaction, and depressive symptoms: a communitybased cross-sectional study among Japanese employees in small-and medium-scale businesses. Oncotarget, 8(32), 53041-53052.

Nonaka, I. \& Takeuchi, H. (1995). The knowledge-creating company. New York: Oxford University Press.

OECD. (2013). OECD Guidelines on Measuring Subjective Well-being, OECD Publishing, Paris.

Oikawa, N., \& Tanner Jr., J.F. (1992). The Influence of Japanese culture on business relationships and negotiations. Journal of Services Marketing, 6(3), 67-74.

Olesen, M. H., Thomsen, D. K., \& O’Toole, M. S. (2015). Subjective well-being: Above neuroticism and extraversion, autonomy motivation matters. Personality and Individual Differences, 77, 45-49.

Piccolo, R., Judge, T., Takahashi, K., Watanabe, N., \& Locke, E. (2005). Core self-evaluations in Japan: relative effects on job satisfaction, life satisfaction, and happiness. Journal Of Organizational Behavior, 26(8), 965-984.

Rain, J. S., Lane, I. M., \& Steiner, D. D. (1991). A current look at the job satisfaction/life satisfaction relationship: Review and future considerations. Human relations, 44(3), 287-307.

Rode, J. C. (2004). Job satisfaction and life satisfaction revisited: A longitudinal test of an integrated model. Human Relations, 57(9), 1205-1230.

Ryan, R., \& Deci, E. (2000). Self-determination theory and the facilitation of intrinsic motivation, social development, and well-being. American Psychologist, 55(1), 68-78.

Ryan, R., \& Deci, E. (2001). On Happiness and Human Potentials: A Review of Research on Hedonic and Eudaimonic Well-Being. Annual Review of Psychology, 52(1), 141-166.

Seo, Y. W., Chae, S. W., \& Lee, K. C. (2015). The impact of absorptive capacity, exploration, and exploitation on individual creativity: Moderating effect of subjective well-being. Computers in Human Behavior, 42, 68-82.

Shimizu, Y. (2011). A study of personnel evaluation system reform in the firm (in Japanese: 企業 における人事評価制度改革についての一考察). Nagoya Gakuin University Journal of Social Science, 47(4), 73-82.

Shimoda, S. A. (2016). Time to Retire: Is Lifetime Employment in Japan Still Viable? Fordham 
International Law Journal, 39(3), 753-790.

Sousa-Poza, A., \& Sousa-Poza, A. (2000). Well-being at work: a cross-national analysis of the levels and determinants of job satisfaction. The Journal of Socio-Economics, 29(6), 517-538.

Spector, P. (1997). Job Satisfaction. Thousand Oaks: SAGE Publications.

Tadokoro, M. (2014). Changed Discourses on Demography in Japan. In Silvio Beretta et al. (eds.), Italy and Japan: How Similar Are They? (pp. 23-46). Milan: Springer.

The Japan Times. (2015). Workforce promotion panel: Extend foreign resident visa limit, put elderly, married women to work. The Japan Times. Retrieved 9 March 2016, from http://www.japantimes.co.jp/news/2015/09/10/business/workforce-promotion-panel-extend-foreignresident-visa-limit-put-elderly-wifes-work/

Trompenaars, F. \& Hampden-Turner, C. (2012). Riding the waves of culture. New York: McGrawHill.

Unanue, W., Gómez, M. E., Cortez, D., Oyanedel, J. C., \& Mendiburo-Seguel, A. (2017). Revisiting the link between job satisfaction and life satisfaction: the role of basic psychological needs. Frontiers in psychology, 8, 680 .

Wall, T., Clegg, C., \& Jackson, P. (1978). An evaluation of the Job Characteristics Model. Journal of Occupational Psychology, 51(2), 183-196.

Wall, T., Corbett, J., Martin, R., Clegg, C., \& Jackson, P. (1990). Advanced manufacturing technology, work design, and performance: A change study. Journal of Applied Psychology, 75(6), 691-697.

Warr, P. (1987). Work, unemployment, and mental health. Oxford: Clarendon Press.

Warr, P. (2007). Work, happiness, and unhappiness. Mahwah, NJ: Lawrence Erlbaum.

Williams, B. (2013). Japan's Demographic Crisis: Security Implications and Obstacles to Resolving an Issue Symptomatic of National Decline. In Andrew Tan (ed.) East and Southeast Asia: International Relations and Security Perspectives, London: Routledge, pp. 267-278.

Yamaguchi, I. (2013). A Japan-US cross-cultural study of relationships among team autonomy, organizational social capital, job satisfaction, and organizational commitment. International Journal of Intercultural Relations, 37(1), 58-71. 


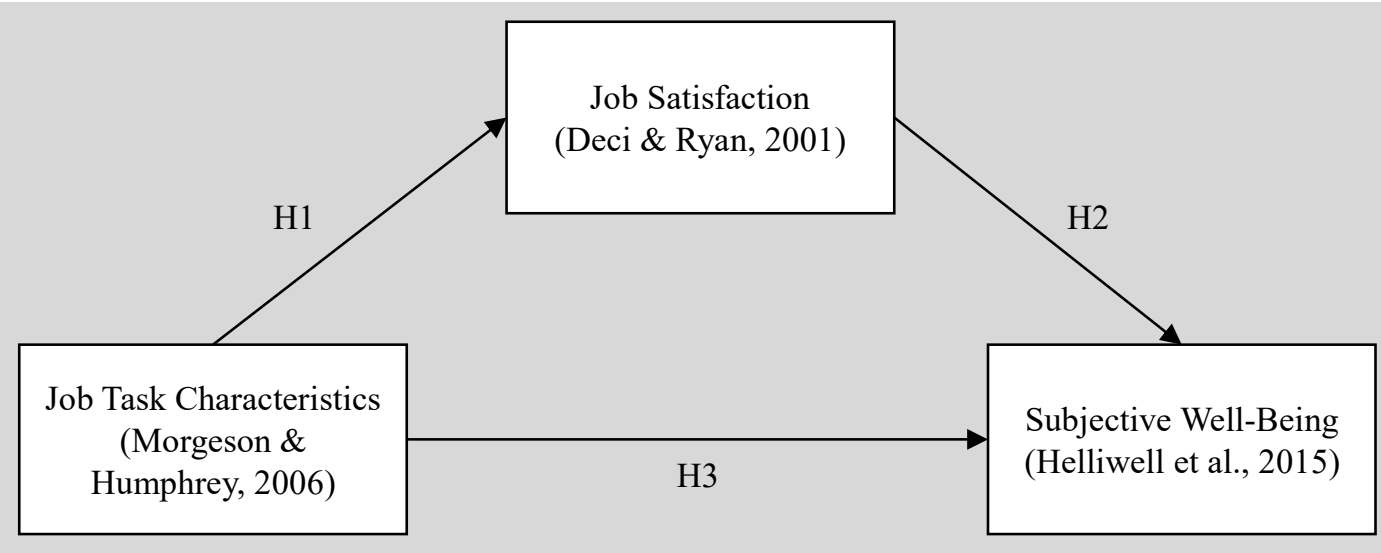

Figure 1. Research model and hypotheses

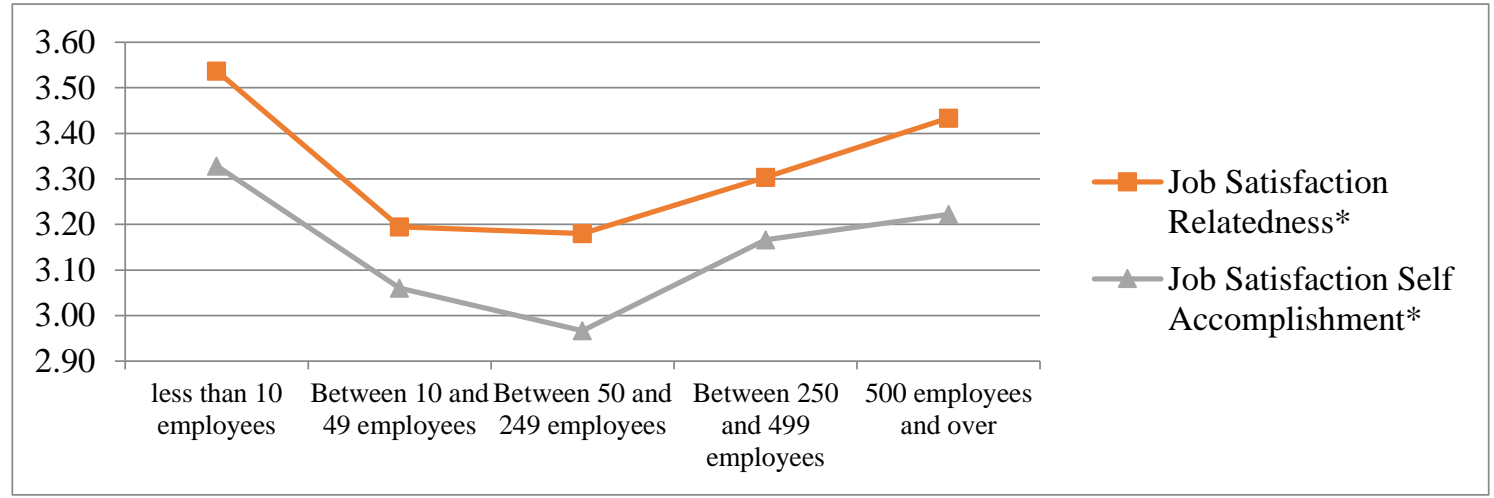

Figure 2. Mean values of job satisfaction factors by company size at location (* differences between groups significant at $\mathrm{p}<0.05$ ) 


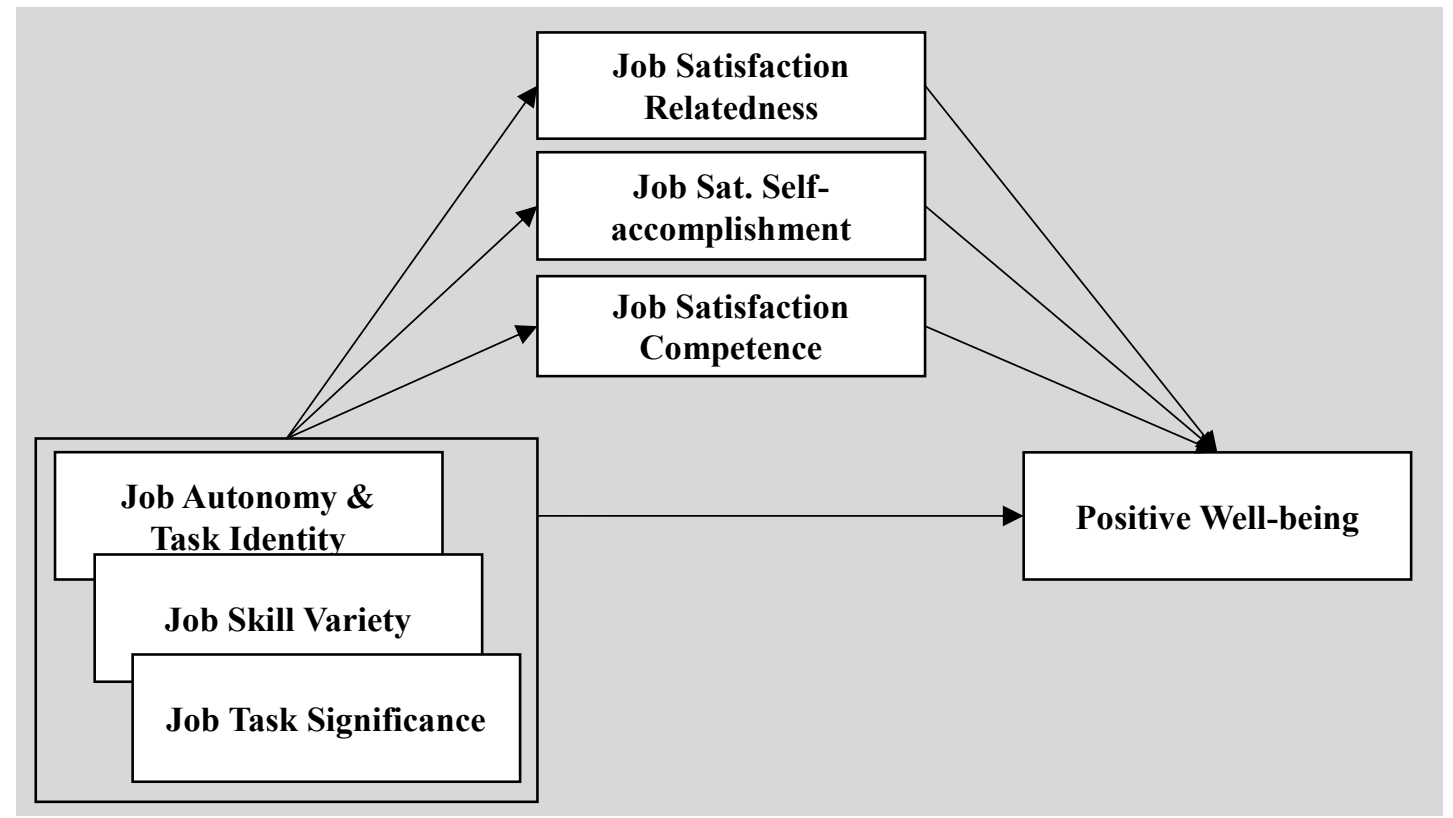

Figure 3. Unmoderated mediation models for each job task characteristic

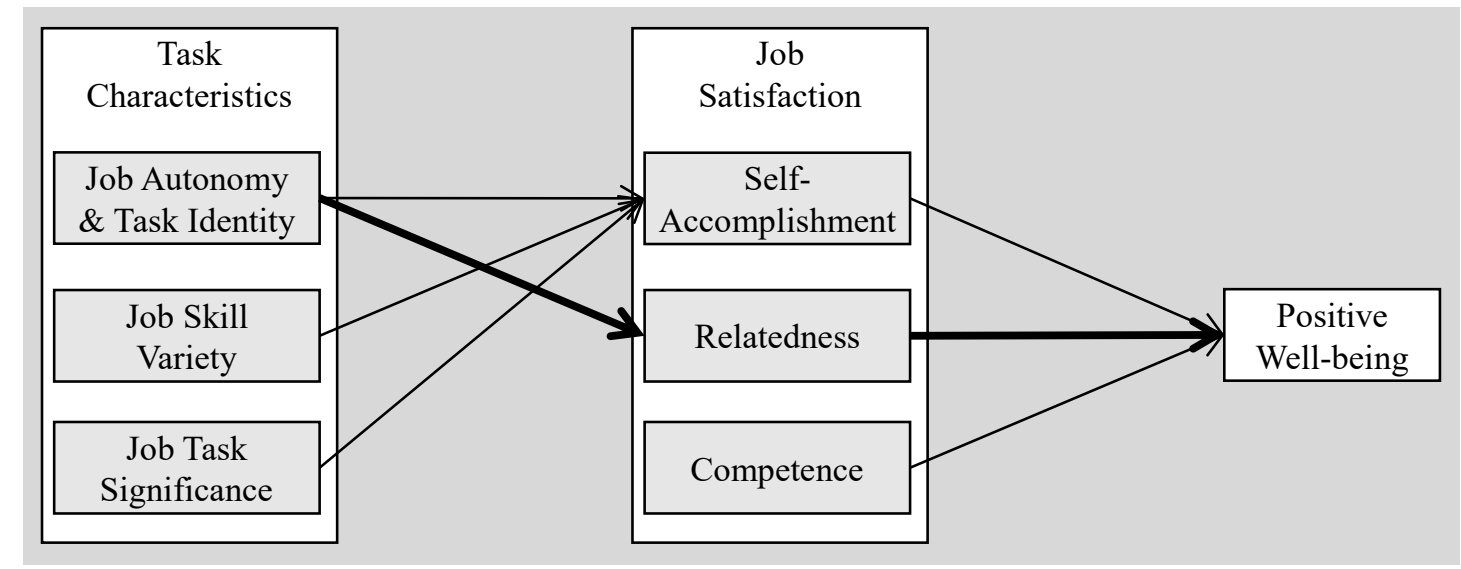

Figure 4. Summary of results for the three unmoderated mediation models (all relationships significant at $\mathrm{p}<0.001)$ 
Table 1. Sample demographics

\begin{tabular}{|c|c|c|c|c|c|}
\hline Indicator & $\mathrm{N}$ & $\%$ & Indicator & $\mathrm{N}$ & $\%$ \\
\hline Gender & & & Company size in subsidiary & & \\
\hline Male & 156 & $\mathbf{7 5 \%}$ & Less than 10 employees & 87 & $42 \%$ \\
\hline Female & 52 & $25 \%$ & Between 10 and 49 employees & 55 & $26 \%$ \\
\hline Age range & & & Between 50 and 249 employees & 32 & $15 \%$ \\
\hline Under 25 & 0 & $0 \%$ & Between 250 and 499 employees & 9 & $4 \%$ \\
\hline $25-29$ & 5 & $2 \%$ & 500 employees and over & 25 & $12 \%$ \\
\hline $30-39$ & 40 & $19 \%$ & Company size in Japan & & \\
\hline $40-49$ & 69 & $33 \%$ & Less than 10 employees & 67 & $32 \%$ \\
\hline $50-59$ & 75 & $36 \%$ & Between 10 and 49 employees & 38 & $18 \%$ \\
\hline 60 and over & 19 & $9 \%$ & Between 50 and 249 employees & 34 & $16 \%$ \\
\hline Years at company & & & Between 250 and 499 employees & 17 & $8 \%$ \\
\hline Under 3 years & 34 & $16 \%$ & 500 employees and over & 52 & $25 \%$ \\
\hline 3-9 years & 56 & $27 \%$ & & & \\
\hline $10-14$ years & 27 & $13 \%$ & Industry & & \\
\hline $15-19$ years & 27 & $13 \%$ & Agriculture and forestry & 2 & $1 \%$ \\
\hline 20 years and over & 64 & $31 \%$ & Fishery & 0 & $0 \%$ \\
\hline Position & & & $\begin{array}{l}\text { Mining and quarrying of stone and } \\
\text { gravel }\end{array}$ & 0 & $0 \%$ \\
\hline Staff & 104 & $50 \%$ & Construction & 16 & $8 \%$ \\
\hline $\begin{array}{l}\text { Section Manager / } \\
\text { Project Manager }\end{array}$ & 47 & $23 \%$ & Manufacturing & 42 & $20 \%$ \\
\hline Department Head & 6 & $3 \%$ & Utilities & 3 & $1 \%$ \\
\hline Division Head & 2 & $1 \%$ & Information and communications & 8 & $4 \%$ \\
\hline Senior / Top Management & 13 & $6 \%$ & Transport and postal acitivites & 5 & $2 \%$ \\
\hline $\begin{array}{l}\text { CEO / Representative } \\
\text { Director }\end{array}$ & 36 & $17 \%$ & Wholesale and retail trade & 18 & $9 \%$ \\
\hline Function & & & Finance and insurance & 11 & $5 \%$ \\
\hline Sales & 35 & $17 \%$ & Real estate, rental and leasing & 7 & $3 \%$ \\
\hline Marketing & 4 & $2 \%$ & $\begin{array}{l}\text { Scientific research, professional } \\
\text { and technical services }\end{array}$ & 5 & $2 \%$ \\
\hline Technology / R\&D & 31 & $15 \%$ & $\begin{array}{l}\text { Accommodations, eating and } \\
\text { drinking services }\end{array}$ & 8 & $4 \%$ \\
\hline $\begin{array}{l}\text { Manufacturing / Quality } \\
\text { Control }\end{array}$ & 23 & $11 \%$ & $\begin{array}{l}\text { Living-related and personal } \\
\text { services and amusement services }\end{array}$ & 4 & $2 \%$ \\
\hline Administration & 30 & $14 \%$ & Education, learning support & 10 & $5 \%$ \\
\hline Senior Management & 13 & $6 \%$ & Medical, healthcare and welfare & 10 & $5 \%$ \\
\hline Other & 72 & $35 \%$ & Compund services & 3 & $1 \%$ \\
\hline Company size at location & & & Services (not elsewhere classified) & 36 & $17 \%$ \\
\hline Less than 10 employees & 71 & $34 \%$ & $\begin{array}{l}\text { Government (except elsewhere } \\
\text { classified) }\end{array}$ & 6 & $3 \%$ \\
\hline $\begin{array}{l}\text { Between } 10 \text { and } 49 \\
\text { emplovees }\end{array}$ & 44 & $21 \%$ & Other & 14 & $7 \%$ \\
\hline $\begin{array}{l}\text { Between } 50 \text { and } 249 \\
\text { employees }\end{array}$ & $\mathbf{5 0}$ & $24 \%$ & & & \\
\hline $\begin{array}{l}\text { Between } 250 \text { and } 499 \\
\text { employees }\end{array}$ & 16 & $8 \%$ & & & \\
\hline 500 employees and over & 17 & $13 \%$ & & & \\
\hline
\end{tabular}


Table 2. Means, standard deviation and correlations

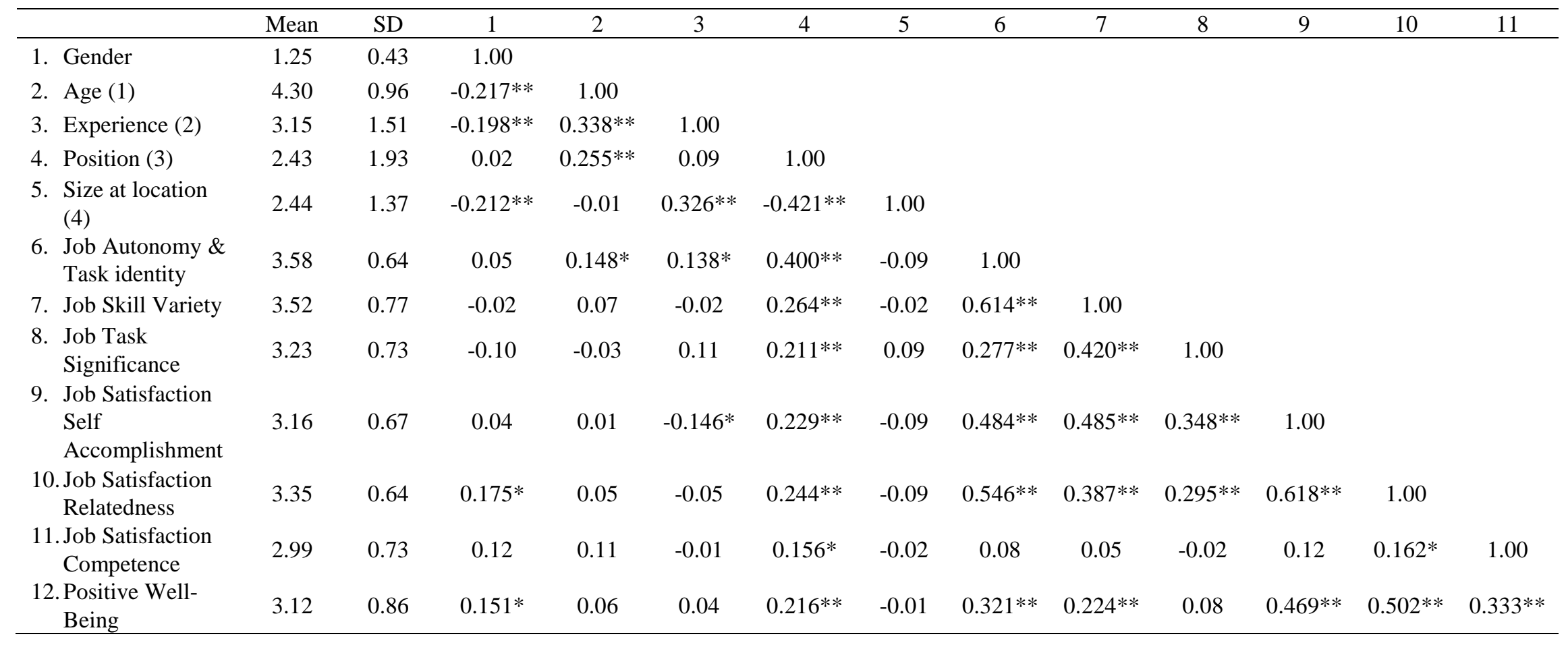

${ }^{*} \mathrm{p}<0.05 ; * * \mathrm{p}<0.01$.

(1) $1:$ under $25 ; 2: 25-29 ; 3: 30-39 ; 4: 40-49 ; 5: 50-59 ; 6: 60$ and over

(2) 1: under 3 years; $2: 3-9$ years; $3: 10-14$ years; $4: 15-19$ years; $5: 20$ years and over

(3) 1: Staff; 2: Section Manager / Project Manager; 3: Department Head; 4: Division Head; 5: Senior / Top Management; 6: CEO / Representative Director

(4) 1: less than 10 employees; 2: Between 10 and 49 employees; 3: Between 50 and 249 employees; 4: Between 250 and 499 employees; 5: 500 employees and over 
Table 3. Total, direct, and indirect effects, regression coefficients, standard errors, and model summary information for the presumed job satisfaction influence multiple mediator model for job autonomy \& task identity

\begin{tabular}{|c|c|c|c|c|c|c|}
\hline & Effect & SE & $\mathrm{t}$ & $\mathrm{p}$ & LLCI & ULCI \\
\hline Total effect of $\mathrm{X}$ on $\mathrm{Y}$ & 0.253 & 0.067 & 3.753 & 0.000 & 0.12 & 0.386 \\
\hline Direct effect of $\mathrm{X}$ on $\mathrm{Y}$ & 0.015 & 0.065 & 0.235 & 0.814 & -0.113 & 0.144 \\
\hline Indirect effect of $\mathrm{X}$ on $\mathrm{Y}$ & Effect & Boot SE & Boot LLCI & Boot ULCI & & \\
\hline TOTAL & 0.238 & 0.059 & 0.131 & 0.366 & & \\
\hline M1 & 0.083 & 0.031 & 0.035 & 0.156 & & \\
\hline M2 & 0.149 & 0.048 & 0.074 & 0.262 & & \\
\hline M3 & 0.006 & 0.02 & -0.035 & 0.051 & & \\
\hline (C1) & -0.066 & 0.057 & -0.198 & 0.027 & & \\
\hline$(\mathrm{C} 2)$ & 0.077 & 0.038 & 0.01 & 0.16 & & \\
\hline (C3) & 0.143 & 0.054 & 0.051 & 0.276 & & \\
\hline
\end{tabular}

\begin{tabular}{|c|c|c|c|c|c|c|c|c|c|c|c|c|}
\hline \multirow{3}{*}{ Antecedent } & \multicolumn{12}{|c|}{ Consequent } \\
\hline & \multicolumn{3}{|c|}{ M1 } & \multicolumn{3}{|c|}{ M2 } & \multicolumn{3}{|c|}{ M3 } & \multicolumn{3}{|c|}{$\mathrm{Y}$} \\
\hline & Coeff & SE & $\mathrm{p}$ & Coeff & SE & $\mathrm{p}$ & Coeff & SE & $\mathrm{p}$ & Coeff & SE & $\mathrm{p}$ \\
\hline $\mathbf{X}$ & 0.238 & 0.068 & 0.001 & 0.408 & 0.064 & 0.000 & 0.022 & 0.070 & 0.753 & 0.015 & 0.065 & 0.814 \\
\hline M1 & - & - & - & - & - & - & - & - & - & 0.348 & 0.060 & 0.000 \\
\hline M2 & - & - & - & - & - & - & - & - & - & 0.365 & 0.063 & 0.000 \\
\hline \multirow[t]{3}{*}{ M3 } & - & - & - & - & - & - & - & - & - & 0.260 & 0.057 & 0.000 \\
\hline & \multirow{2}{*}{\multicolumn{3}{|c|}{$\begin{array}{c}\mathrm{R}^{2}=0.057 \\
\mathrm{~F}(1,206)=12.352 \\
\mathrm{p}=0.001\end{array}$}} & \multirow{2}{*}{\multicolumn{3}{|c|}{$\begin{array}{c}R^{2}=0.167 \\
F(1,206)=41.166, \\
p=0.000\end{array}$}} & \multirow{2}{*}{\multicolumn{3}{|c|}{$\begin{array}{c}\mathrm{R}^{2}=0.000 \\
(1,206)=0.100, \\
\mathrm{p}=0.753\end{array}$}} & \multicolumn{3}{|c|}{$\mathrm{R}^{2}=0.330$} \\
\hline & & & & & & & & & & $\mathrm{F}(4$ & $\begin{array}{l}203)=2 \\
\mathrm{p}=0.00\end{array}$ & \\
\hline
\end{tabular}

X (Job Autonomy \& Task Identity); Y (Positive Well-Being); M1 (Job Satisfaction Self-Accomplishment); M2 (Job Satisfaction Relatedness); M3 (Job Satisfaction Competence); C1 (Job Satisfaction SelfAccomplishment minus Job Satisfaction Relatedness); C2 (Satisfaction Self-Accomplishment minus Job Satisfaction Competence); C3 (Job Satisfaction Relatedness minus Job Satisfaction Competence) 
Table 5. Total, direct, and indirect effects, regression coefficients, standard errors, and model summary information for the presumed job satisfaction influence multiple mediator model for job task significance

\begin{tabular}{|c|c|c|c|c|c|c|}
\hline & Effect & SE & $\mathrm{t}$ & $\mathrm{p}$ & LLCI & ULCI \\
\hline Total effect of $\mathrm{X}$ on $\mathrm{Y}$ & 0.034 & 0.07 & 0.488 & 0.626 & -0.103 & 0.171 \\
\hline Direct effect of $\mathrm{X}$ on $\mathrm{Y}$ & -0.105 & 0.06 & -1.751 & 0.081 & -0.222 & 0.013 \\
\hline Indirect effect of $\mathrm{X}$ on $\mathrm{Y}$ & Effect & Boot SE & Boot LLCI & Boot ULCI & & \\
\hline TOTAL & 0.139 & 0.064 & 0.015 & 0.271 & & \\
\hline M1 & 0.101 & 0.045 & 0.02 & 0.199 & & \\
\hline M2 & 0.048 & 0.039 & -0.03 & 0.121 & & \\
\hline M3 & -0.01 & 0.024 & -0.054 & 0.044 & & \\
\hline (C1) & 0.053 & 0.055 & -0.05 & 0.171 & & \\
\hline (C2) & 0.11 & 0.057 & -0.003 & 0.221 & & \\
\hline (C3) & 0.057 & 0.046 & -0.033 & 0.151 & & \\
\hline
\end{tabular}

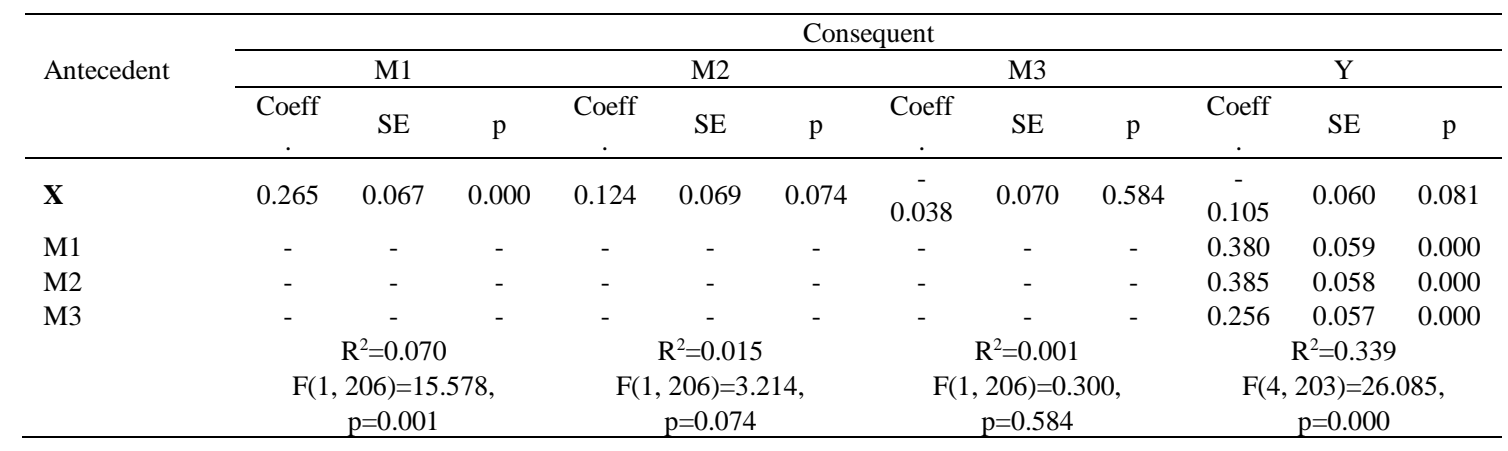

X (Job Task Significance); Y (Positive Well-Being); M1 (Job Satisfaction Self-Accomplishment); M2 (Job Satisfaction Relatedness); M3 (Job Satisfaction Competence); C1 (Job Satisfaction Self-Accomplishment minus Job Satisfaction Relatedness); C2 (Satisfaction Self-Accomplishment minus Job Satisfaction Competence); C3 (Job Satisfaction Relatedness minus Job Satisfaction Competence) 